\title{
Phosphorus Source and Availability Modulate the Rhizosphere Bacterial Community Assembly in Common Bean
}

Josiane Barros Chiaramonte

Embrapa Environment https://orcid.org/0000-0001-8583-794X

Harold Alexander Vargas-Hoyos

Embrapa Environment

Lilian Simara Abreu Soares Costa

Embrapa Environment

Maike Rossmann

Embrapa Environment

Daiana Alves Silva

Agronomic Institute

Davide Bulgarelli

The James Hutton Institute

Rodrigo Mendes ( $\nabla$ rodrigo.mendes@embrapa.br)

https://orcid.org/0000-0002-9817-4118

Research

Keywords: Rhizosphere microbiome, Phosphorus nutrition, Microbial ecology, Network analysis, Common bean

Posted Date: August 6th, 2020

DOI: https://doi.org/10.21203/rs.3.rs-51077/v1

License: (a) (1) This work is licensed under a Creative Commons Attribution 4.0 International License. Read Full License 


\section{Abstract \\ Background}

Phosphorus $(\mathrm{P})$ availability is the main nutritional factor that limits crops yields in tropical soils due to edaphic processes that lead to $\mathrm{P}$ immobilization after mineral fertilization. Considering the potential of the rhizosphere microbiome to transform insoluble $\mathrm{P}$ into forms readily available for plant uptake, in this study is proposed that plants with contrasting $P$ uptake efficiency, growing under depleted amounts of $P$ are able to shape distinct bacterial communities in the rhizosphere enriching taxa specialized in $\mathrm{P}$ mobilization.

\section{Methods}

We selected two common bean genotypes contrasting in $\mathrm{P}$ efficiency uptake and grew them in a soil with a gradient of two different sources of $P$, triple superphosphate (TSP) or rock phosphate Bayovar (RPB). The rhizosphere bacterial community was assessed by $16 \mathrm{~S}$ rRNA amplicon sequencing. Data analyses focused in describing the structure of the bacterial communities, identification of OTUs differentially enriched in different treatments, functional metagenomic prediction and cooccurrence network.

\section{Results}

$P$ sources and levels resulted in different rhizosphere bacterial community structure. A high number of differentially enriched OTUs were observed under P depleted conditions in the P-inefficient genotype, mainly belonging to Actinobacteria phylum. The P-inefficient genotype did not show significant differences in the rhizosphere bacterial community assembly growing in different $\mathrm{P}$ sources. Predicted metagenome profiles showed the enrichment of bacterial functions involved in P mobilization, in the rhizosphere of the $\mathrm{P}$ inefficient genotype cultivated in $\mathrm{P}$ depleted conditions. The network analysis revealed that in the rhizosphere of the P-inefficient genotype under $\mathrm{P}$ depleted conditions the bacterial community has a higher number of nodes and edges, higher average degree and clustering coeficient when compared to the treatment with optimal P level.

\section{Conclusion}

Our data showed that the uptake of exogenous input resulted in the assembly of a P-competent microbiome in the P-inefficient genotype compared to the efficient one, supporting the hypothesis that the selective pressure for the $\mathrm{P}$ uptake engages $\mathrm{P}$-inefficient genotypes in symbiotic relationships with the soil microbiome. These results will pave the way for future experimentation aiming at explore the contribution of this P-competent microbiome to plant growth and development in a range of soil type. 


\section{Background}

Agriculture demands about $90 \%$ of the global phosphorus $(P)$ production [1]. Along with the rapid world population growth and the increasing demand for food, there is a significant rise of human exploitation of soil resources including P. Current models project a $40-60 \%$ depletion of $P$ resources by the year 2100 [2] which, in turn, will negative impact on agricultural production [3, 4]. Ironically, about $30 \%$ of the world soils show a high capacity of fixing phosphates $[5,6]$. In Brazil, which is one of the main world suppliers of agriculture products, since 1960 the application of phosphate fertilizers largely exceeds plant demands causing a significant accumulation in the soil profile [7]. This soil legacy $P$ represents an important resource to mitigate the global $\mathrm{P}$ crisis consisting in a suitable strategy to promote agricultural sustainability [7].

A pivotal role in mobilizing $\mathrm{P}$ legacy in soils is played by the soil microbiome. While the role of mycorrhiza is well-known for plant P-uptake, we have a limited knowledge regarding the contribution of bacterial communities [8]. Bacteria inhabiting the soil are able to solubilize inorganic $\mathrm{P}$ and mineralize organic compounds converting stable $P$ fractions into soluble phosphate ions $[9,10]$, mainly through the production and secretion of organic acids, that act as chelators of metal ions releasing orthophosphates $[11,12]$. Evidence shows that phosphatases from microorganisms are more efficient in the release of orthophosphates [13], and that they are activated under $P$ depleted conditions [14-16], even in natural environments [17]. The activity of soil microbial communities enables the application of insoluble sources of phosphate in agriculture [18], without compromising the yield [19, 20]. Therefore, understanding the contribution of the rhizosphere microbiome on $\mathrm{P}$ mobilization is a key pre-requisite towards the development of sustainable strategies conjugating reduced reliance on $\mathrm{P}$ applications with profitable crop yields.

The genetic composition of the host plant is one of the determinants of the rhizosphere microbiome, often referred to as the "host-genotype" effect [21, 22]. In this context, common bean plants are considered a good model to study plant-microbiome interactions [23, 24], however, the specific contribution of mineral elements, such as $P$, in these interactions is poorly understood. In this study, we hypothesized that a common bean genotype less efficient in $\mathrm{P}$ uptake, when growing under $\mathrm{P}$-depleted conditions, relies on the rhizosphere microbiome to mitigate the lack of $P$ by enriching the rhizosphere with $\mathrm{P}$ mobilizing microorganisms. This hypothesis was tested by comparing the rhizosphere bacterial communities of two common bean genotypes contrasting in phosphate uptake efficiency, i.e. P-efficient and P-inefficient, growing in a gradient of triple superphosphate (TSP) or rock phosphate Bayovar (RPB). Our results demonstrate how $\mathrm{P}$ source and availability modulate the rhizosphere bacterial community assembly in common bean, revealing that the host plant depends, at least in part, on its bacterial community for $\mathrm{P}$ uptake.

\section{Material And Methods}

\section{Common bean genotypes and phosphorus sources}


The common bean genotypes selected, IAC-Imperador (P-efficient) and Dor-364 (P-inefficient), were previously characterized in hydroponics studies as efficient and inefficient in P uptake [25]. We selected two sources of phosphate based on their solubility, triple superphosphate (TSP), which is a readily available source, and rock phosphate Bayovar (RPB), which relies mainly on plant exudates and microorganisms' activity to become available $[20,26]$.

\section{Quantification of phosphate fixation in the soil}

To establish the soil P gradient used in the bioassay, we set up an experiment to quantify the phosphate fixation in the soil. This analysis allowed us to predict the amount of phosphate that should be added in the soil to obtain the desired amounts of phosphate for each treatment (Supplementary Fig. 1). Five levels of phosphate: $15,30,60,120$, and $240 \mathrm{~kg} \mathrm{ha}^{-1}$ of $\mathrm{P}_{2} \mathrm{O}_{5}$, from triple superphosphate (TSP) or rock phosphate Bayovar (RPB), were added to $200 \mathrm{ml}$ pots containing soil and kept under greenhouse conditions ( $27.4^{\circ} \mathrm{C}, 24 \%$ humidity) for 10 days keeping constant soil moisture (70\%). The sources of $\mathrm{P}_{2} \mathrm{O}_{5}$ were triple superphosphate (TSP, $46 \% \mathrm{P}_{2} \mathrm{O}_{5}$ ) ground in ball mill for $1 \mathrm{~min}$; and phosphate rock Bayovar $\left(31 \% \mathrm{P}_{2} \mathrm{O}_{5}, 4.42 \% \mathrm{SiO}_{2}, 0.96 \% \mathrm{Al}_{2} \mathrm{O}_{3}, 0.87 \% \mathrm{Fe}_{2} \mathrm{O}_{3}, 46 \% \mathrm{CaO}, 0.53 \% \mathrm{MgO}, 1.98 \% \mathrm{Na}_{2} \mathrm{O}, 0.3 \% \mathrm{~K}_{2} \mathrm{O}\right.$, $0.01 \% \mathrm{MnO})$, ground for $10 \mathrm{~min}$. By the end of the test, each pot was analysed to quantify the available $P$ (Supplementary Fig. 2), by colorimetric method extracted with ion exchange resin at the Laboratory of Soils, Embrapa Environment, Jaguariúna, SP.

\section{Experimental Design and Bioassay}

The experiment was conducted under greenhouse conditions according to a factorial scheme considering two plant genotypes (P-efficient and P-inefficient), two sources of P (TSP and RBP) and four-level gradient of $\mathrm{P}$, in completely randomized design with five replicates. For the $\mathrm{P}$ gradient, we used $\mathrm{P}$ depleted conditions (LO, without P amendment) and amendments corresponding to 50\% (L50), 100\% (L100) and $200 \%$ (L200), of the advised P required to a high production of common bean (Supplementary Table 1, Supplementary Fig. 3). The soil used in the experiment was obtained from the experimental field of Embrapa Environment, Jaguariúna, SP. We selected a representative soil for tropical conditions, with low $\mathrm{P}$ content (4 $\left.\mathrm{mg} \mathrm{dm}^{-3}\right)$, low $\mathrm{pH}$ (4.6) and with no history of $\mathrm{P}$ fertilization (Supplementary Table 2).

The experiment was conducted under greenhouse conditions, in $5 \mathrm{~L}$ pots containing $4.5 \mathrm{~kg}$ of soil, kept under field capacity varying from 60 to $70 \%$. The moisture was reset once or twice every day using water or nutrient solution containing $\mathrm{Ca}\left(\mathrm{NO}_{3}\right)_{2} \cdot 4 \mathrm{H}_{2} \mathrm{O}(0.2 \mathrm{mM})$ and $\mathrm{Mg}\left(\mathrm{NO}_{3}\right)_{2} \cdot 6 \mathrm{H}_{2} \mathrm{O}(0.03 \mathrm{mM})$, which was used every 10 days until flowering state (R6) when sampling was performed. Total supply of $\mathrm{N}$ in each pot by the end of the experiment was $900 \mathrm{mg}\left(720 \mathrm{mg}\right.$ via $\mathrm{Ca}\left(\mathrm{NO}_{3}\right)_{2} \cdot 4 \mathrm{H}_{2} \mathrm{O}$ and $180 \mathrm{mg}$ via $\left.\mathrm{Mg}\left(\mathrm{NO}_{3}\right)_{2} \cdot 6 \mathrm{H}_{2} \mathrm{O}\right)$. The average temperature along the experiment varied between 17 and $29^{\circ} \mathrm{C}$, conditions mimicking common bean growth in sub-tropical climates and natural photoperiod around $10 \mathrm{~h} / 14 \mathrm{~h}$ (light/dark). 


\section{Phenotypic characterization of common bean}

To verify phenotypic differences between the genotypes, were performed analysis of relative chlorophyll index (RChl) by non-destructive methods (SPAD-502Plus - Konica Minolta), height (H), and shoot diameter (ShDi) during stage V3 (first trifoliate leaf fully expanded), i.e. before the appearance of $P$ depletion deficiency symptoms. The same parameters were analysed when the first symptoms began to appear during the end of the vegetative stages (V4-R5). During the flowering stage (R6), besides RChl, $\mathrm{H}$ and ShDi; the number of nodes per plant (NPP) was also verified, and after the sampling of the rhizosphere the roots were storage in $20 \%$ ethylic alcohol for structure analysis. The images of each root were obtained in scanner LA2400 (EPSON) and the traits were calculated using software WinRHIZO® (Regent Instruments Inc., Quebec, Canada), considering total root length (TRL), root superficial area (RSA), root total volume (RTV) and average diameter (RoDi). After the structural analysis, roots were air dried at room temperature until constant weight to determine root dry biomass (RDB). Right after the sampling, leaves were digitalized in Multifunctional Officejet 4400 (HP), and total leaf area (TLA) was accessed by calibrating the scan with a known area and using parameters to calculate all the leaves digitalized (SupplementaryFile2_TotalLeafArea.cpp). The leaves were dried in air forced oven $\left(50^{\circ} \mathrm{C}\right)$ until constant weight to determine the shoot dry biomass (SDB). The evaluation of $\mathrm{P}$ content in the leaves were carried out through nitric perchloric digestion (Sarruge and Haag, 1974).

\section{Bacterial community assessment by $16 \mathrm{~S}$ rRNA amplicon sequencing}

The metagenomic DNA was extracted from $250 \mathrm{mg}$ of rhizosphere using Power Soil DNA Extraction TM kit ${ }^{\circledR}$ (MoBio) following the manufacturer's instructions. The DNA was extracted from two replicates for each sample and them pooled together. DNA quality was accessed using NanoDrop ${ }^{\mathrm{TM}} 2000 / 2000 \mathrm{c}$ Spectrophotometer and 0.8\% Agarose gel. Quantification was performed on Qubit ${ }^{\circledR} 2.0$ Fluorometer (Invitrogen, USA), using Qubit ${ }^{\circledR}$ ds DNA HS Assay kit according to manufacturer's instructions. A total of

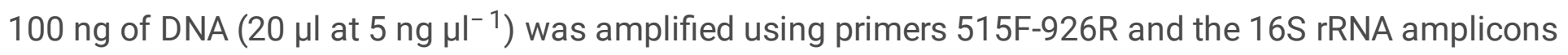
were sequenced at Argonne National Laboratory (USA).

\section{Taxonomical annotation and data analysis}

The sequences obtained from the 16S rRNA amplicon sequencing were pre-processed using QIIME v.1.9 [27]. The forward and reverse reads generated were joint using fastq-join method (ARONESTY, 2011), followed by demultiplexing, removal of barcode and primer sequences. Quality filtering of the sequences was performed, and the sequences were truncate considering the Phred Quality threshold higher than Q20. After identification and removal of chimera using Usearch Database [28], de novo Operational Taxonomic Unit (OTU) picking was performed by assigning similar sequences to OTUs, selecting the representative OTUs, PyNAST alignment [27]; and taxonomy classification was attributed considering 
Silva's database SSU_115 [29]. After the removal of chloroplast and mitochondria-related sequences, the pipeline followed to multivariate analysis. After accessing the differences between the bulk soil and rhizosphere of both common bean genotypes in the constrained coordination analysis (CAP), the effect of each factor, genotype, P-level and P-source, was analysed by a Permutational Multivariate Analysis of Variance (PERMANOVA) to access the effect of each factor in the rhizosphere microbial community using the function ADONIS in Vegan Package [30,31]. The constrained ordination analysis was performed considering Bray Curtis as distance index using the function Ordinate in R software Phyloseq Package [32]. After verifying the existence of the rhizosphere effect, the bulk soil samples were removed to visualize the effect of the genotypes tested.

Further, to verify the differences between P-depleted conditions and P-amended soil, the different enriched OTUs were assessed with DESeq2 Package [33], in R environment (R Development Core Team, 2008). In this analysis the dispersion of the OTU counts were estimated by empirical Bayes shrinkage, which fits a generalized linear model (GLM) to OTU abundances with the treatments as explanatory variables. The input data consisted in a matrix containing raw counts of sequencing of reads [33,34], after removing OTUs with less than 15 reads in each treatment. The visualization of differentially enriched OTUs was performed on ITOL [35].

\section{Functional prediction}

The prediction of the functions based on 16S rRNA sequencing was performed with function Tax4Fun [36] available at R Environment (R Development Core Team, 2008) in the OTU Table containing taxonomic information according to Silva's database [29]. Tax4Fun pipeline was used for functional community profiling based on $16 \mathrm{~S}$ rRNA data to add information on the predicted rhizosphere community metabolism. Tax4Fun links 16S rRNA sequences with functional annotation with a nearest neighbour identification based on a minimum sequence similarity; this tool aggregated to the SILVA-based 16S rRNA computed using QIIME corresponds up to $95 \%$ of the whole metagenome in soil samples [36]. Then, the differentially enriched functions (KeGG orthology, KO) were accessed using a non-parametrical T-Test performed on QIIME [27]. A list of 46 KEGG functions (Supplementary Table 3) involved in P metabolism was selected to analyze separately in a more specifically level with a non-parametrical T-test performed on QIIME v.1.9 [27].

\section{Cooccurrence Network Analysis}

The direct and indirect interactions among community members and the nature of this association in response to $\mathrm{P}$ levels were analysed by constructing a co-occurrence network with SPARCC correlations [37]. The impact of rare OTUs were minimized by removing OTUs observed fewer than 15 times in each treatment. A total of 99 correlations were performed to estimate the pairwise relation and the count data was permutated 100 times to generate randomized tables. The correlations obtained for the real data were compared to the shuffled data; and only pairwise correlations higher than 0.9 and $p$ values bellow 
0.001 were considered as significant interactions, suggesting strong evidence for association. The visualization of the network was performed in Gephi [38].

\section{Results}

\section{Impact of phosphorus sources and levels on plant development}

As expected, P-efficient cultivar showed higher levels of relative chlorophyll index and height compared to P-inefficient cultivar (Supplementary Table 4) in the early stages of plant development (V3). During later stages (V4 and R5), these differences were restricted only to chlorophyll index (Supplementary Table 5). In these stages (V4-V5), in both genotypes were observed the effect of the $P$ levels amendment, treatments with higher amounts of $\mathrm{P}$ resulted in plants showing better development in height, shoot diameter and relative chlorophyll index (Supplementary Fig. 4). Plant relative chlorophyll index, shoot diameter, shoot dry weigh, root structure and root dry weight (Supplementary Table 6) were used to confirm that the conditions achieved during the experiment were robust to access and evaluate the rhizosphere microbiome of common bean genotypes contrasting in $\mathrm{P}$ uptake efficiency growing in distinct phosphates sources gradient (Supplementary Fig. 5).

\section{Host control of the rhizosphere assembly under different phosphorus sources and levels}

Out of the 16S rRNA amplicon sequencing output, 10,656 OTUs were used for analysis after data preprocessing and filtering (Supplementary Table 7). A strong rhizosphere effect was observed in both common bean cultivars as bulk soil samples clustered apart from rhizosphere samples (Fig. 1a). Bulk soil samples showed higher diversity when compared to rhizosphere bacterial communities as indicated by Shannon index calculation (Supplementary Fig. 6).

To identify the factors underpinning with the rhizosphere community assembly, a permutational multivariate analysis (PERMANOVA) was performed, which allowed us to identify a significant effect of both the plant genotype $\left(\mathrm{R}^{2}=0.03 ; p=0.032\right.$, Supplementary Table 8$)$ and $\mathrm{P}$ level $\left(\mathrm{R}^{2}=0.05 ; p=0.006\right.$, Supplementary Table 8). Intriguingly, the effect of $\mathrm{P}$ source was genotype-dependent, as showed by the significant interaction between the genotype and $P$ source $\left(R^{2}=0.06 ; p=0.006\right.$, Supplementary Table 8$)$. This is also demonstrated in the constrained ordination analysis for $P$ sources. In the rhizosphere of the P-efficient cultivar, the rhizosphere bacterial community structure was significant different when soil was amended with TSP or RPB. For the P-inefficient cultivar, only L200 of TSP showed significant differences in the rhizosphere assembly (Supplementary Fig. 7).

In IAC Imperador [P-efficient] grown in soil amended with TSP, constrained analysis of principal coordinates explained $16.6 \%$ of the data variance (ANOVA, $F=2.52, p=0.001$, Fig. 1b). The lowest $P$ 
addition (L50) did not show any effect in microbial community structure when compared to depleted $P$ (L0), but levels L100 and L200 showed a different clustering pattern (Fig. 1b). When this cultivar was grown in soil amendment with RPB, constrained analysis of principal components, explained $14 \%$ of data variance (ANOVA, $F=2.04, p=0.001$, Fig. $1 \mathrm{c}$ ). In this case, while samples from L50 and L100 treatments clustered, the most constrating P leves (LO and L200) showed different bacterial community structures (Fig. 1c).

In Dor-364 [P-inefficient] cultivar grown with TSP amendment, constrained analysis of principal coordinates showed significant differences between $P$ levels, explaining $21.7 \%$ of the data variance $(F=$ 2.75, $p=0.001$, Fig. 1d). The P depleted (L0) and the highest P addition (L200) resulted in different communities' structures, while addition intermediate levels (L50 and L100) showed a similar clustering pattern. With the RPB amendment, each different level of $\mathrm{P}$ showed distinct patterns of bacterial community structure, the constrained principal coordinate analysis explained $20.1 \%$ of data variance (ANOVA, $\mathrm{F}=2.47, p=0.001$, Fig. 1e).

For both plant genotypes and P sources, the bacterial communities structures in P depleted (LO) condition and in the treatment using the optimal amount of $P(L 100)$ were significantly different (Fig. 1).

\section{Taxonomical assembly under phosphorus depleted conditions}

To gain further insights into the bacteria underpinning the observed community diversification, we used differential anylsis to identify bacterial taxa significatively more abundant in the community assembled under depleted P (L0) when compared with community assembled under the advised level of P (L100).

For both plant genotypes and P sources, most of the differentially enriched OTUs were found in the rhizosphere amended with optimal levels of P (L100), except for IAC Imperador [P-efficient], where five OTUs belonging to Proteobacteria (1 Alphaproteobacteria, 1 Betaproteobacteria and 1 Gammaproteobacteria), Bacteroidetes (1 OTU) and Armatimonadetes (1 OTU) were enriched under P depeleted conditions and two OTUs where enriched in rhizosphere amended with L100-TPS (Fig. 2a). Seventeen OTUs belonging mainly to Proteobacteria (5 Alphaproteobacteria, 1 Betaproteobacteria and 2 Deltaproteobacteria) and to Bacteroidetes (4 OTUs) were significatively more abundant in P depleted as compared to L100-RPB (Fig. 2b). In Dor-364 [P-inefficient], 20 OTUs, belonging to Actinobacteria (9 OTUs), Proteobacteria (4 Alphaproteobacteria, 1 Gammaproteobacteria), Bacteroidetes (4 OTUs), Firmicutes (1 OTU) and 1 unclassified OTU were enriched in depleted P levels when compared to L100-TSP (Fig. 2c). When rhizosphere P depleted condition was compared to L100-RPB, 72 OTUs were enriched in L0 belonging to Proteobacteria (20 Alphaproteobacteria, 9 Betaproteobacteria, 1 Deltaproteobacteria and 1 Gammaproteobacteria), Actinobacteria (16 OTUs), Bacteroidetes (11 OTUs), Firmicutes (2 OTUs), Chloroflexi (1 OTU), Acidobacteria (1 OTU) and 10 unclassified OTUs (Fig. 2d). It is important to highlight that the amendment with RPB resulted in a significant enrichment of the phylum Acidobacteria (120 


\section{Functional assembly under phosphorus depleted conditions on Dor-364 [P-inefficient] genotype}

Most of the differentially enriched OTUs were observed in the Dor-364 [P-inefficient] genotype when compared with the P-efficient genotype and considering the hypothesis that the infefficient genotype would rely more on its microbiome for $\mathrm{P}$ mobilization, we focused further analysis on the functional assembly of this genotype under $P$ depleted condition (LO) comparing with the advised amendment (L100) of TSP or RPB. The number of predicted KEGG functions involved in P mobilization was significantly higher under $\mathrm{P}$ depleted condition (LO). While 25 functions involved in $\mathrm{P}$ transport and mineralization were enriched in L0, only 11 functions were enriched in L100-TSP (Fig. 3). When comparing P depleted (L0) with rhizosphere amended with optimal P level (L100) of RPB, 40 functions were enriched in L0 and 28 functions in L100 (Fig. 3). Under P limiting conditions predicted functions like, acid and alkaline phosphatase enzymatic activity, phosphate transport systems and phytase activity are significantly differentially enriched (Fig. 3). As for IAC Imperador [P-efficient], P-depleted condition and Poptimal addition of TSP did not show differentially enriched functions involved in P cycle (Supplementary Table 9).

\section{Complexity of bacterial community interactions in Dor-364 [P-inefficient] rhizosphere}

P additions modulated the structure of the rhizosphere community in Dor-364 [P-inefficient] (Fig. 4). Under depleted $\mathrm{P}$, the bacterial community showed a higher number of nodes and edges, higher average degree and clustering coeficient, which are significantly lower with optimal amendment of TSP or RPB (Table 1). In the other hand, when $\mathrm{P}$ is not a limiting factor there is an increase in the modularity and in the number of communities, resulting in a network with lower diameter. These effects were more pronounced in the comparison when RPB was used as P source, which also showed a higher number of nodes and even smaller diameter when compared to P depleted conditions and TSP amendment. The order Ktenodobacteriales (Chloroflexy) consisted the node with higher betweeness centrality in P depleted conditions, while Caulobacter (Alphaproteobacteria) and Acidobacteriales (Acidobacteria) showed higher betweeness centrality under TSP and RPB amendments, respectively. 
Table 1

\begin{tabular}{|c|c|c|c|}
\hline $\begin{array}{l}\text { Network analysis of Dor-36 } \\
\text { bacterial communities. De } \\
\text { common bean growing in } \\
\text { amended with triple supe } \\
\text { phosphate Bayovar (RPB) } \\
\text { the advised P require }\end{array}$ & $\begin{array}{l}\text { [P-Inef } \\
\text { iled ne } \\
\text { deplete } \\
\text { hosph } \\
\text { orresp } \\
\text { o a hig }\end{array}$ & $\begin{array}{l}\text { cient] rh } \\
\text { vork sta } \\
\text { soil (LC } \\
\text { te (TSP) } \\
\text { iding to } \\
\text { produc }\end{array}$ & $\begin{array}{l}\text { osphere } \\
\text { stics of } \\
\text { or soils } \\
\text { r rock } \\
00 \% \text { of } \\
\text { on. }\end{array}$ \\
\hline Network parameters & LO & TSP & RPB \\
\hline & & L100 & L100 \\
\hline Number of nodes & 354 & 161 & 209 \\
\hline Number of edges & 1432 & 171 & 211 \\
\hline Positive Edges & 853 & 104 & 121 \\
\hline Negative Edges & 579 & 67 & 90 \\
\hline Modularity & 0.37 & 0.880 & 0.880 \\
\hline Number of communities & 35 & 48 & 38 \\
\hline Network Diameter & 8 & 6 & 4 \\
\hline Average Path Length & 2.77 & 1.840 & 1.510 \\
\hline Average Degree & 8.09 & 1.870 & 2.020 \\
\hline Clustering Coefficient & 0.083 & 0.022 & 0.035 \\
\hline
\end{tabular}

\section{Discussion}

\section{Host control of the rhizosphere assembly under different phosphorus levels and sources}

Among different factors impacting the rhizosphere assembling, the host exerts a significant effect on modulating the rhizosphere community structure. A previous study comparing the assembly of bacterial communities in wild and modern common bean, showed that plant genotype explained $31.2 \%$ of the variation observed in the rhizosphere microbial community when considering microbiome abundance distances [24]. Here, considering only P-dependent recruitment cues, was observed a significant rhizosphere effect of 4\% of IAC Imperador [P-efficient], and 6\% of Dor-364 [P-inefficient] compared to bulk soil, and a genotype effect of $3 \%$ regarding abundance distances between the two evaluated plant genotypes, and the interaction between the different management ( $P$ source) and different genotypes also have significant impacts in the rhizosphere, about $6 \%$ considering abundance distance matrices.

Long term rock fertilization showed significant changes in the rhizosphere of maize compared to TSP fertilization [39]. Different sources of $P$ caused an effect in the rhizosphere that was host genotype 
dependent. The P-efficient plant genotype showed distinct bacterial communities' structures under different sources of P (Supplementary Fig. 6), while the P-inefficient genotype did not. Possibly the efficient genotype is better adapted to soluble sources of $\mathrm{P}$, recognizing RPB as P depleted condition and requiring a different assembly of bacterial community structure with RPB. On the other hand, the Pinefficient genotype is more dependent on its rhizosphere microbiome resulting in similar communities' structures in both sources of $P$.

Deficiency of $\mathrm{P}$ in plants might impact the cell permeability, leading to modified exudation patterns [40]; consequently, $\mathrm{P}$ availability is also important in the rhizosphere microbial composition. When considering each source of $P$ separately, we observe that it has a significant effect of the level. A small addition of $P$ (both from TSP or RPB) exerted a priming effect in the rhizosphere of Dor-364 [P-inefficient] not observed in IAC Imperador [P-efficient] (Fig. 1b, C, d, e). Possibly, the plant stress caused by the lack of P limited the richness and diversity of microorganisms in the rhizosphere of Dor-364 [P-inefficient] under $\mathrm{P}$ depleted conditions (Supplementary Fig. 5).

Castrillo [41] showed in Arabidopsis that genotypic changes in the hosts regarding the response to $\mathrm{P}$ stressed conditions showed significant differences in the rhizosphere assembly, being more correlated with bacterial community structure than with the level of inorganic $P$ stored in the plant. This finding indicates that the rhizosphere community did not respond to the levels of $P$ fertilizations as the plant phenotype does, suggesting that the P-efficient plant genotype appears to be less dependent on the rhizosphere microbiome for $\mathrm{P}$ uptake.

\section{Rhizosphere taxonomical assembly under phosphorus depleted conditions}

While the P-efficient common bean responds better to $\mathrm{P}$ amendments in terms of plant development, the P-inefficient common bean is more responsive in terms of changing the rhizosphere microbiome structure. How changes in the rhizosphere microbial community affect plant physiology and development is far from being completely elucidated, therefore there is no consensus of what consists in a specialized microbiome for $P$ efficiency. Bergkemper et al., (2016), suggested that the microbial community in $P$ depleted conditions is assembled to increase the levels of $\mathrm{P}$ in forest soil, and then identified that Solibacteriales, Acidobacteriales and Actinomycetales, showed important role in the $\mathrm{P}$ cycling processes. Here, we also found that Acidobacteriales was predominantly enriched in the P-inefficient plant genotype specially when RPB was used for P amendment (TSP enriched 40 OTUs and RPB 48 enriched OTUs).

In a study aiming to identify the effects of long-term fertilization in the P cycle, Grafe et al [42] identified that Verrucomicrobiaceae, Sphingomonadaceae, Anaerolinaceae, Planctomycetaceae, Chitniphagaceae, Acidibacteriaceae and Bradyrhizobiaceae are involved in the regulation of $\mathrm{P}$ cycling, mobilization of organic or inorganic phosphates and uptake. In the same study other families like Rhodocyclaceae, Chlorobiaceae, Geobacteriaceae, Flavobacteriaceae, Opitutaceae, Verrucomicrobiaceae and 
Solibacteriaceae have mainly copiotrophic behaviour, and are involved only in the uptake of $\mathrm{P}$ and do not apply energy to mobilize it from the soil. Here, the rhizosphere bacteria community structure of IAC Imperador [P-efficient] under $\mathrm{P}$ depleted conditions showed consistently (when compared to the rhizosphere amended with both sources of P, Fig. 2a,b) an increase in the phyla Alphaproteobacteria (Sphingomonadaceae) and Bacteroidetes (Chitinophagaceae). The family Sphingomonadaceae was described to be pioneers colonizers of biofilms [43,44], suggesting a oligotrophic life strategy, also, a genus of this family was described to promote plant growth in endophytic conditions (Khan et al., 2014). Its role in $\mathrm{P}$ cycle occurs since the regulation, mobilization and acquisition in soil amended with nitrogen and organic matter [42]. The family Chitinophagaceae is also involved in different phases of P cycle, which is a feature of oligotrophic organisms, unlike those organisms that do not disposal energy in $P$ mobilization [42].

In Dor-364 [P-inefficient] the consistent enrichment under $\mathrm{P}$ depleted conditions, when compared to the rhizosphere amended with both sources of $\mathrm{P}$, besides the enrichment of Bacteroidetes (Chitinophagaceae), an enrichment of Actinobacteria (Micrococcaceae) was also observed. Previous studies correlated the Micrococcaceae family to higher concentrations of carbon and nitrogen [46], however, its role in P cycle are still poorly explored [47], and some authors attribute an copiotrophic growth strategy to this group [48, 49]. In IAC Imperador [P-efficient], Alphaproteobacteria was enrichment in $\mathrm{P}$ depleted conditions, especially when compared to RPB amended treatments, the enriched bacterial families were Beijerinckiaceae, Bradyrhizobiaceae, Caulobacteraceae, Hyphomicrobiaceae, Methylobacteriaceae, Phyllobacteriaceae, Rhizobiaceae, Sphingomonadaceae and Xanthobacteraceae. The bacterial families, Burkholderiaceae, Comamonadaceae and Oxalobacteriaceae, belonging to Betaproteobacteria, were also enriched in P depleted conditions when compared to RPB amendment treatment. Most of these bacterial families were previously reported as $P$ mobilizing bacteria $[9,50]$. This suggests that the amendment with phosphate of difficult solubilization (RPB) selected only a few bacterial groups able to use this resource, favouring the enrichment of a smaller number of differentially enriched OTU when compared to treatments amended with a readily available P source (TSP).

Several subgroups of Acidobacteria and also the family Acidobacteriales (representing 120 differentially enriched OTUs) were enriched in the rhizosphere of DOR-364 [P-inefficient] with RPB amendment, highlighting the importance of this group to solubilize inorganic phosphate. This phylum was described to be involved in several transformations of the P cycle, including mobilization and uptake [17, 42]. This fact highlights the better responsiveness of the rhizosphere microbiome of Dor-364 [P-inefficient] to phosphate amendment from both P sources, but with a more pronounced effect when RPB was used for amendments, which demands a higher microbial activity to make it available. This fact suggests that Dor-364 [P-inefficient] structures a more competitive microbiome. Regardless of the directions of these interactions, our results provide fundamentally novel insights into the molecular basis of plantmicrobiome interactions for P-uptake in the rhizosphere which, in turn, can be deployed by plant breeders to sustainably enhance bean production. 
Due to the functional redundancy and the existence of taxa closely phylogenetic related presenting different metabolic rates and involvement in soil processes [51], it is important to take into account not only the composition, but also the functional assembly of the bacterial communities. In a previous study, different long-term management of fertilizers in soil showed significant changes in bacterial community structure, despite of not affecting the abundance of genes involved in P cycle [42]. In this context, it is important to analyse the functional potential of the rhizosphere microbiome regarding $\mathrm{P}$ mobilization and uptake.

\section{Functional assembly under phosphorus depleted conditions on phosphorus inefficient genotype}

The shaping of a microbial community specialized towards $\mathrm{P}$ cycling when $\mathrm{P}$ is limited was already described for forest soils [17] and other studies related low $P$ availability to changes in soil microbial communities [52, 53]. Despite of not being responsive to $P$ addition in terms of growth, Dor-364 [Pinefficient] showed an improvement of several functions involved in $\mathrm{P}$ metabolism when exposed to $\mathrm{P}$ depleted conditions. The abundance of genes potentially involved in the regulation of phosphate transport and uptake (mainly two component systems regulons) were higher under $\mathrm{P}$ depleted conditions and, consequently, functions involved in extracellular mobilization and uptake of organic and inorganic $P$ in the soil (alkaline phosphatase, phytase, PQQGDH) were also enriched. Many studies have already reported the overexpression of these genes and activation of enzymes under P depleted conditions [41, 54]. Interestingly, in the rhizosphere of IAC Imperador [P-efficient], this enrichment was not observed in plants growing under $\mathrm{P}$ depleted condition. This fact reinforces that the P-efficient common bean uses another strategy to supply its demand for $\mathrm{P}$ not being dependent on the microbiome as the P-inefficient common bean, which enriches bacteria potentially involved in the P cycle under depleted P. It is therefore tempting to speculate that, the efficiency of IAC Imperador [P-efficient] occurs due to physiological adaptations, like root development, selected during plant breeding [55-58] at the expense of the establishment of the symbiotic interactions with rhizosphere microorganisms. In this sense, the absence of these phenotypic traits in Dor-364 [P-inefficient] genotype underpinned its higher reliance on its rhizosphere microbiome for $\mathrm{P}$ use.

The P-source emerged as another recruitment cue shaping the Dor-364 microbiome. For instance, the amendment with RPB was responsible for a higher number of differentially enriched functions involved mainly in organic P mobilization, further suggesting the ability of Dor-364 [P-inefficient] of engaging with a microbiome better equipped to mobilise organic fertilizers. This occurs mainly due to the assembly a rhizosphere microbial community specialized in exploring organic $P$ from the soil, once even in the presence of insoluble $\mathrm{P}$ source the community was shaped to explore organic $\mathrm{P}$. It is possible that this is responsible for this genotype classification as non-responsive to $P$ amendment. Only one function involved in $\mathrm{P}$ solubilization, that is PQQGDH, was differentially enriched in the $\mathrm{P}$ depleted conditions compared to optimal $\mathrm{P}$ amendment (with both TSP and RPB) in P inefficient genotype. Inorganic $\mathrm{P}$ is mainly released by the chelation of metallic phosphate ions in the soil $[59,60]$. The higher number of 
functions involved in organic P uptake suggests that Dor-364 [P-inefficient] is more efficient in the use of organic sources of $P$, but this needs to be further investigated.

\section{Complexity of bacterial community interactions on phosphorus inefficient genotype}

Visualising the rhizosphere community structure through network analysis allowed us to observe that Dor-364 [P-inefficient] has significant higher number of organisms (nodes) and associations (edges) under $\mathrm{P}$ depleted condition than with $\mathrm{P}$ optimal level. However, once the average path length, that determines the average cohesion between nodes [61] was higher under $P$ depleted conditions, and the diameter, which is the largest distance between a pair of nodes, is higher under $\mathrm{P}$ depleted conditions, the community network in low $\mathrm{P}$ is looser when compared with bacterial communities assembled under $\mathrm{P}$ optimal level.

Modularity, which corresponds to a group of nodes highly connected between which other and with a few links with other collection of nodes [62], can be proportional to the response of a community during a disturbance [63]. This feature was higher with $\mathrm{P}$ amendment, suggesting that these conditions are highly resilient, and therefore any disturbance in the environment could be softened by the rhizosphere bacterial community functional redundancy. This pattern was observed for both P sources.

The betweenness centrality of a node, is responsible for the identification of possible keystone species in a given network $[62,64]$. In the rhizosphere of Dor-364, an OTU representing the order Ktedonobacteriales (Chloroflexi) probably consist in a keystone specie to structure the community under $\mathrm{P}$ depleted conditions. Very few information of this order is found due to the fact that only few representatives are cultivated [65], but it was already described as keystone species, being part of a core rhizosphere microbiome in sugarcane [66]. Amendments with different sources of $P$ resulted in different keystone species identified by the betweenness centrality. With TSP amendment, the keystone specie in the rhizosphere of Dor-364 [P-inefficient] was an OTU belonging to the family Caulobacteriaceae (Alphaproteobacteria) and with RBP additions, an OTU from the family Acidobacteriaceae Subgroup 1 (Acidobacteria). The importance of Caulobacteriaceae in soils and its role in recalcitrant organic matter degradation was recently described $[67,68]$. Acidobacteriaceae is ubiquitous in several environments, including soils, and members of this subgroup were already reported as plant growth promotion rhizobacteria with ability to solubilize inorganic phosphate [69].

\section{Conclusion}

Our findings support the hypothesis that the selective pressure for the uptake of exogenous input deequipped P-responsive genotypes with their capacity of engaging in symbiotic relationships with the soil microbiome. In turn this resulted in the assembly of a P-competent microbiome in the P-inefficient genotypes compared to efficient ones. The experimental and computational resources developed here will 
place us in the position to experimental test these scenarios in future experimentations across a range of soil types, setting the stage for future experimentation aiming at discerning the contribution of this $\mathrm{P}$ competent microbiome to plant growth, development and health.

\section{Declarations}

\section{Ethics approval and consent to participate}

Not applicable.

\section{Consent for publication}

Not applicable.

\section{Availability of data and material}

Raw data of the bacterial 16S rRNA amplicon sequence are publicly available in MG-RAST (https://www.mg-rast.org/linkin.cgi?project=mgp95034). Statistical and bioinformatic analyses workflow and pipelines are available at https://github.com/JosianeChiaramonte/Statistics-and-bioinformatic.

\section{Competing interests}

The authors declare no conflict of interest.

\section{Funding}

Grant 2015/14680-9 São Paulo Research Foundation (FAPESP), Grant 2017/14063-5 São Paulo Research Foundation (FAPESP), Coordination of Superior Level Staff Improvement (CAPES), and National Council for Scientific and Technological Development (CNPq 302337/2016-4, 302591/219-2, 381679/2019-5 and 403959/2019-5).

\section{Authors' contributions}

JBC was responsible for the experimental design, bioassays conduction, samples processing, bioinformatics and statistical analyses and writing the manuscript. HAVH, LSS, MR collaborated in bioassays conduction, sampling and scientific discussions. DAS provided the seeds and contributed for selecting plant genotypes, experimental design and scientific discussions. DB collaborated in the data analysis, scientific discussions and writing. RM coordinated all steps of the study, since experimental design and bioassays conduction, sampling, data analysis, discussion and writing of the manuscript. 


\section{Acknowledgements}

We thank Cristiano Alberto de Andrade for the technical support to establish the P gradient levels.

\section{References}

1. Smil V. P HOSPHORUS IN THE E NVIRONMENT: Natural Flows and Human Interferences. Annu Rev Energy Environ. 2000;25:53-88.

2. Van Vuuren DP, Bouwman AF, Beusen AHW. Phosphorus demand for the 1970-2100 period: A scenario analysis of resource depletion. Glob Environ Chang. 2010;20:428-39.

3. Cordell D, White S. Tracking phosphorus security: indicators of phosphorus vulnerability in the global food system. Food Secur. 2015;7:337-50.

4. Leghari SJ, Buriro M, Jogi Q, Kandhro MN, Leghari AJ. Depletion of Phosphorus Reserves, a Big Threat To Agriculture: Challenges and Opportunities. Sci Int. 2016;28:2697-702.

5. Kochian L V. Rooting for more phosphorus The rate of human mutation. Nature. 2012;:6-7.

6. van de Wiel CCM, van der Linden CG, Scholten OE. Improving phosphorus use efficiency in agriculture: opportunities for breeding. Euphytica. 2016;207:1-22.

7. Withers PJA, Rodrigues M, Soltangheisi A, De Carvalho TS, Guilherme LRG, Benites VDM, et al. Transitions to sustainable management of phosphorus in Brazilian agriculture. Sci Rep. 2018;8:113.

8. Püschel $D$, Janoušková $M$, Voříšková A, Gryndlerová $H$, Vosátka $M$, Jansa J. Arbuscular Mycorrhiza Stimulates Biological Nitrogen Fixation in Two Medicago spp. through Improved Phosphorus Acquisition. Front Plant Sci. 2017;8 March:1-12.

9. Rodríguez H, Fraga R. Phosphate solubilizing bacteria and their role in plant growth promotion. Biotechnol Adv. 1999;17:319-39.

10. Singh JS, Pandey VC, Singh DP. Efficient soil microorganisms: A new dimension for sustainable agriculture and environmental development. Agric Ecosyst Environ. 2011;140:339-53.

11. Khan MS, Zaidi A, Musarrat J. Phosphate Solubilizing Microorganisms. 2014.

12. Marra LM, de Oliveira-Longatti SM, Soares CRFS, de Lima JM, Olivares FL, Moreira FMS. Initial pH of medium affects organic acids production but do not affect phosphate solubilization. Brazilian $\mathrm{J}$ Microbiol. 2015;46:367-75.

13. Tarafdar JC, Yadav RS, Meena SC. Comparative efficiency of acid phosphatase originated from plant and fungal sources. J Plant Nutr Soil Sci. 2001;164:279-82.

14. Cabugao KG, Timm CM, Carrell AA, Childs J, Lu T-YS, Pelletier DA, et al. Root and Rhizosphere Bacterial Phosphatase Activity Varies with Tree Species and Soil Phosphorus Availability in Puerto Rico Tropical Forest. Front Plant Sci. 2017;8 October:1-14.

15. Eder S, Shi L, Jensen K, Yamane K, Hulett FM. A Bacillus subtilis secreted phosphodiesterase/alkaline phosphatase is the product of a Pho regulon gene, phoD. Microbiology. 
1996;142:2041-7.

16. Wanner BL. Gene regulation by phosphate in enteric bacteria TL - 51. J Cell Biochem. 1993;51 VNr:47-54.

17. Bergkemper F, Schöler A, Engel M, Lang F, Krüger J, Schloter M, et al. Phosphorus depletion in forest soils shapes bacterial communities towards phosphorus recycling systems. Environ Microbiol. 2016;18:1988-2000.

18. Khan AA, Jilani G, Akhtar MS, Saqlan SM, Rasheed M. Phosphorus Solubilizing Bacteria: Occurrence, Mechanisms and their Role in Crop Production. J Agric Biol Sci. 2009;1:48-58.

19. Goenadi D H, Siswanto, Sugiarto Y. Bioactivation of Poorly soluble phosphate rocks with a phosphorus-solubilizing fungus. Soil Sci Soc Am J. 2000;64:927-32.

20. Cabello M, Irrazabal G, Bucsinszky AM, Saparrat M, Schalamuk S. Effect of an arbuscular mycorrhizal fungus, Glomus mosseae, and a rock-phosphate-solubilizing fungus, Penicillium thomii, on Mentha piperita growth in a soilless medium. J Basic Microbiol. 2005;45:182-9.

21. Bulgarelli D, Garrido-Oter R, Münch PC, Weiman A, Dröge J, Pan Y, et al. Structure and function of the bacterial root microbiota in wild and domesticated barley. Cell Host Microbe. 2015;17:392-403.

22. Schlaeppi K, Bulgarelli D. The plant microbiome at work. Mol Plant-Microbe Interact. 2015;28:212-7.

23. Pérez-Jaramillo JE, Mendes R, Raaijmakers JM. Impact of plant domestication on rhizosphere microbiome assembly and functions. Plant Mol Biol. 2016;90:635-44.

24. Pérez-Jaramillo JE, De Hollander M, Ramírez CA, Mendes R, Raaijmakers JM, Carrión VJ. Deciphering rhizosphere microbiome assembly of wild and modern common bean (Phaseolus vulgaris) in native and agricultural soils from Colombia. Microbiome. 2019;7:1-16.

25. Silva D, Antônio J, Esteves DF, Messias U, Teixeira A, Guilherme J, et al. Efficiency in the use of phosphorus by common bean genotypes. Sci Agric. 2014;71:232-9.

26. de Amaral Leite A, de Souza Cardoso AA, de Almeida Leite R, de Oliveira-Longatti SM, Filho JFL, de Souza Moreira FM, et al. Selected bacterial strains enhance phosphorus availability from biocharbased rock phosphate fertilizer. Ann Microbiol. 2020;70.

27. Caporaso JG, Kuczynski J, Stombaugh J, Bittinger K, Bushman FD, Costello EK, et al. QIIME allows analysis of high- throughput community sequencing data. Nat Publ Gr. 2010;7:335-6.

28. Edgar RC. Search and clustering orders of magnitude faster than BLAST. Bioinformatics. 2010;26:2460-1.

29. Quast C, Pruesse E, Yilmaz P, Gerken J, Schweer T, Yarza P, et al. The SILVA ribosomal RNA gene database project: Improved data processing and web-based tools. Nucleic Acids Res. 2013;41:5906.

30. Anderson MJ. A new method for non parametric multivariate analysis of variance. Austral Ecol. 2001;26:32-46.

31. Dixon P. Computer program review VEGAN, a package of R functions for community ecology. 2003;14:927-30. 
32. Mcmurdie PJ, Holmes S. phyloseq: An R Package for Reproducible Interactive Analysis and Graphics of Microbiome Census Data. 2013;8.

33. Love MI, Anders S, Huber W. Differential analysis of count data - the DESeq2 package. 2014.

34. Mcmurdie PJ, Holmes S. Waste Not, Want Not: Why Rarefying Microbiome Data Is Inadmissible. 2014;10.

35. Letunic I, Bork P. Interactive tree of life (iTOL) v3: an online tool for the display and annotation of phylogenetic and other trees. Nucleic Acids Res. 2016;44:W242-5.

36. Aßhauer KP, Wemheuer B, Daniel R, Meinicke P. Sequence analysis Tax4Fun: predicting functional profiles from metagenomic 16S rRNA data. 2015;31 May:2882-4.

37. Friedman J, Alm EJ. Inferring Correlation Networks from Genomic Survey Data. PLoS Comput Biol. 2012;8:1-11.

38. Bastian M, Heymann S, Jacomy M. Gephi: An Open Source Software for Exploring and Manipulating Networks. Third Int AAAI Conf Weblogs Soc Media. 2009;:361-2.

39. Silva UC, Medeiros JD, Leite LR, Morais DK, Cuadros-Orellana S, Oliveira CA, et al. Long-term rock phosphate fertilization impacts the microbial communities of maize rhizosphere. Front Microbiol. 2017;8 JUL:1-11.

40. Tawaraya K, Horie R, Shinano T, Wagatsuma T, Saito K, Oikawa A. Metabolite profiling of soybean root exudates under phosphorus deficiency. Soil Sci Plant Nutr. 2014;60:679-94.

41. Castrillo G, Teixeira PJPL, Paredes SH, Law TF, De Lorenzo L, Feltcher ME, et al. Root microbiota drive direct integration of phosphate stress and immunity. Nature. 2017;543:513-8.

42. Grafe M, Goers M, von Tucher S, Baum C, Zimmer D, Leinweber P, et al. Bacterial potentials for uptake, solubilization and mineralization of extracellular phosphorus in agricultural soils are highly stable under different fertilization regimes. Environ Microbiol Rep. 2018;10:320-7.

43. Li L, Jeon Y, Lee SH, Ryu H, Santo Domingo JW, Seo Y. Dynamics of the physiochemical and community structures of biofilms under the influence of algal organic matter and humic substances. Water Res. 2019;:136-45.

44. de Vries HJ, Beyer F, Jarzembowska M, Lipińska J, van den Brink P, Zwijnenburg A, et al. Isolation and characterization of Sphingomonadaceae from fouled membranes. npj Biofilms Microbiomes. 2019;5:1-9.

45. Khan AL, Waqas M, Kang SM, Al-Harrasi A, Hussain J, Al-Rawahi A, et al. Bacterial endophyte Sphingomonas sp. LK11 produces gibberellins and IAA and promotes tomato plant growth. $J$ Microbiol. 2014;52:689-95.

46. Schlatter DC, Paul NC, Shah DH, Schillinger WF, Bary Al, Sharratt B, et al. Biosolids and Tillage Practices Influence Soil Bacterial Communities in Dryland Wheat. Microb Ecol. 2019;:737-52.

47. Shen P, Murphy DV, George SJ, Lapis-Gaza H, Xu M, Gleeson DB. Increasing the size of the microbial biomass altered bacterial community structure which enhances plant phosphorus uptake. PLoS One. 2016;11:1-22. 
48. Morrissey EM, Mau RL, Schwartz E, Caporaso JG, Dljkstra P, Van Gestel N, et al. Phylogenetic organization of bacterial activity. ISME J. 2016;10:2336-40.

49. Ho A, Di Lonardo DP, Bodelier PLE. Revisiting life strategy concepts in environmental microbial ecology. FEMS Microbiol Ecol. 2017;93:1-14.

50. Marra LM, Oliveira SM De, Roberto C, Sousa F, Maria F, Moreira DS. Solubilisation of inorganic phosphates by inoculant strains from tropical legumes. Sci Agric. 2011;68:603-9.

51. Allison SD, Martiny JBH. Resistance, resilience, and redundancy in microbial communities. Light Evol. 2009;2:149-66.

52. Huang J, Hu B, Qi K, Chen W, Pang X, Bao W, et al. Effects of phosphorus addition on soil microbial biomass and community composition in a subalpine spruce plantation. Eur J Soil Biol. 2016;72:3541.

53. Zeng Q, Wu X, Wang J, Ding X. Phosphate solubilization and gene expression of phosphatesolubilizing bacterium Burkholderia multivorans WS-FJ9 under different levels of soluble phosphate. J Microbiol Biotechnol. 2017;27:844-55.

54. Redel Y, Staunton S, Durán P, Gianfreda L, Rumpel C, Mora MDLL. Fertilizer P uptake by cereal plant species determined by changes in soil $\mathrm{P}$ fractionation and phosphatase activity. J soil Sci plant Nutr. 2018.

55. Chiorato AF, Carbonell SAM, Carvalho CRL, Nishijima VL, Barros P De, Borges WLB, et al. `IAC IMPERADOR' : early maturity " carioca " bean cultivar. Crop Breed Appl Biotechnol. 2012;12:297300.

56. Silva DA da, Esteves JA de F, Messias U, Teixeira A, Gonçalves JGR, Chiorato AF, et al. Efficiency in the use of phosphorus by common bean genotypes. Sci Agric. 2014;71:232-9.

57. Silva DA da, Esteves JA de F, Gonçalves JGR, Azevedo CVG, Ribeiro T, Chiorato AF, et al. Evaluation of common bean genotypes for phosphorus use efficiency in Eutrophic Oxisol. Bragantia. 2016;75:152-63.

58. Vance CP, Uhde-Stone C, Allan DL. Phosphorus aquisition and use: critical adaptations by plants for securing a nonrewable resource. New Phytol. 2003;157:423-47.

59. Lucy M, Reed E, Glick BR. Applications of free living plant growth-promoting rhizobacteria. Antonie Van Leeuwenhoek. 2004;86:1-25.

60. Gyaneshwar P, Naresh Kumar G, Parekh LJ, Poole PS. Role of soil microorganisms in improving P nutrition of plants. Plant Soil. 2002;245:83-93.

61. Zhou J, Deng Y, Luo F, He Z, Tu Q, Zhi X. Functional molecular ecological networks. MBio. 2010;1:e00169-10.

62. Poudel R, Jumpponen A, Schlatter DC, Paulitz TC, McSpadden Gardener BB, Kinkel LL, et al. Microbiome networks: A systems framework for identifying candidate microbial assemblages for disease management. Phytopathology. 2016;106:1083-96. 
63. Faust K, Raes J. Microbial interactions: From networks to models. Nat Rev Microbiol. 2012;10:53850.

64. Borgatti SP. Centrality and network flow. Soc Networks. 2005;27:55-71.

65. Yabe S, Aiba Y, Sakai Y, Hazaka M, Yokota A. Thermogemmatispora onikobensis gen. nov., sp. nov. and Thermogemmatispora foliorum sp. nov., isolated from fallen leaves on geothermal soils, and description of Thermogemmatisporaceae fam. nov. and Thermogemmatisporales ord. nov. within the class Ktedonob. Int J Syst Evol Microbiol. 2011;61:903-10.

66. Hamonts K, Trivedi P, Garg A, Janitz C, Grinyer J, Holford P, et al. Field study reveals core plant microbiota and relative importance of their drivers. Environ Microbiol. 2018;20:124-40.

67. Wilhelm RC. Following the terrestrial tracks of Caulobacter - redefining the ecology of a reputed aquatic oligotroph. ISME J. 2018;12:3025-37.

68. Wilhelm RC, Singh R, Eltis LD, Mohn WW. Bacterial contributions to delignification and lignocellulose degradation in forest soils with metagenomic and quantitative stable isotope probing. ISME J. 2019;13:413-29.

69. Kielak AM, Cipriano MAP, Kuramae EE. Acidobacteria strains from subdivision 1 act as plant growthpromoting bacteria. Arch Microbiol. 2016;198:987-93.

\section{Figures}
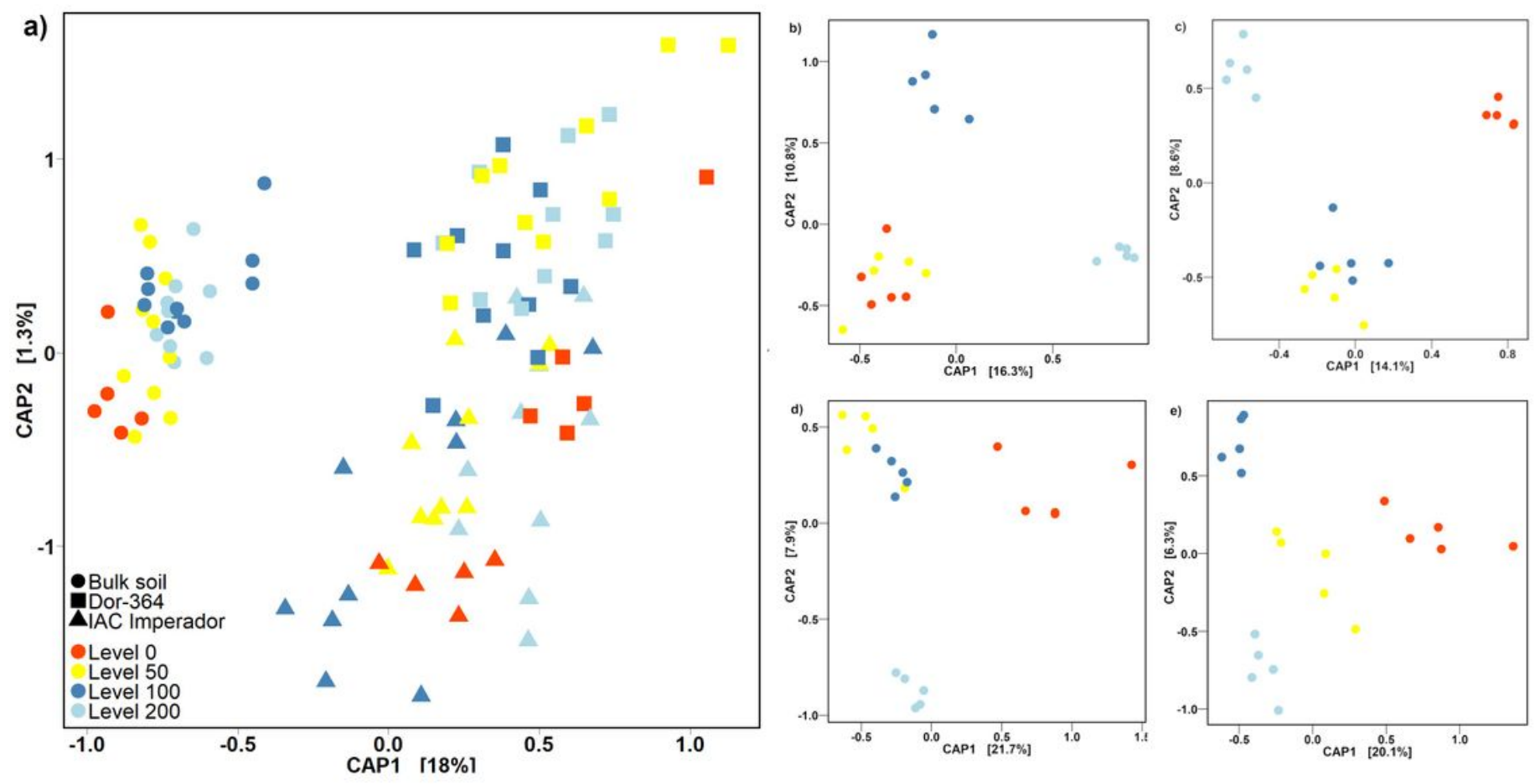

Figure 1 
Bacterial communities structure in the rhizosphere of common bean. Plants were evaluated under different levels of $\mathrm{P}$ and the accessed by $16 \mathrm{~S}$ rRNA amplicon sequencing. Constrained analysis of principal coordinates showing a) overall bacterial community structure across all treatments, b) IAC Imperador [P-efficient] genotype growing under 4-level gradient of triple super phosphate (TSP) or C) rock phosphate bayovar (RPB), and d) Dor-364 [P-inefficient] genotype growing under 4-level gradient of TSP or e) RPB. Different shapes and colours indicate plant genotypes or bulk soil and P-levels, respectively.

a)

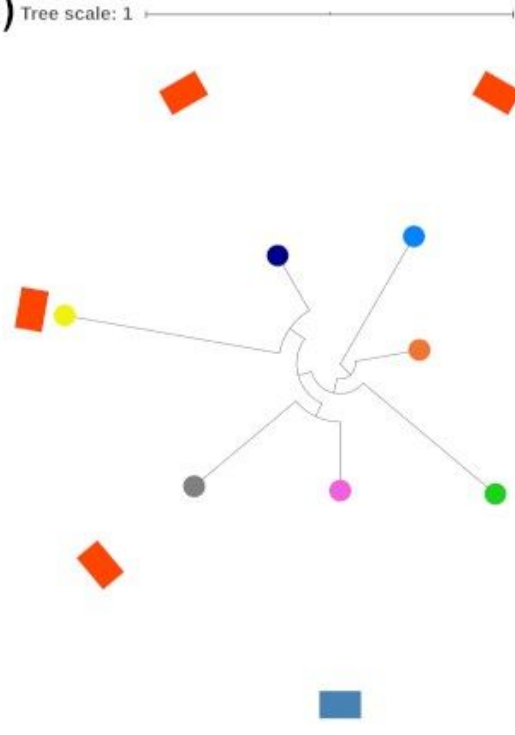

c)

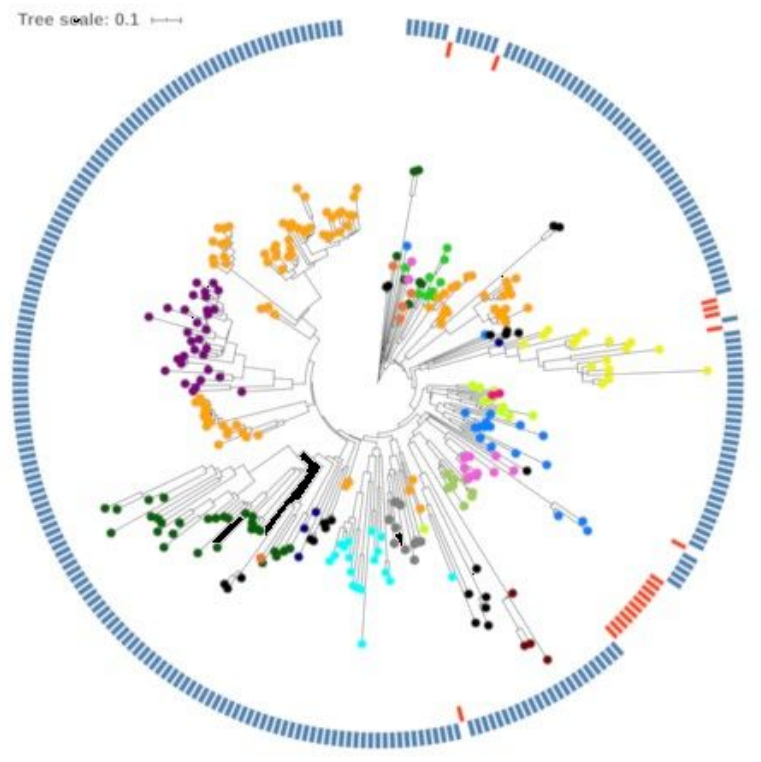

Taxonomy

Alphaproteobacteria Betaproteobacteria

Gamaproteobacteria Deltaproteobacteria
Acidobacteria Bacteroidetes Firmicutes

Verrucomicrobia b)

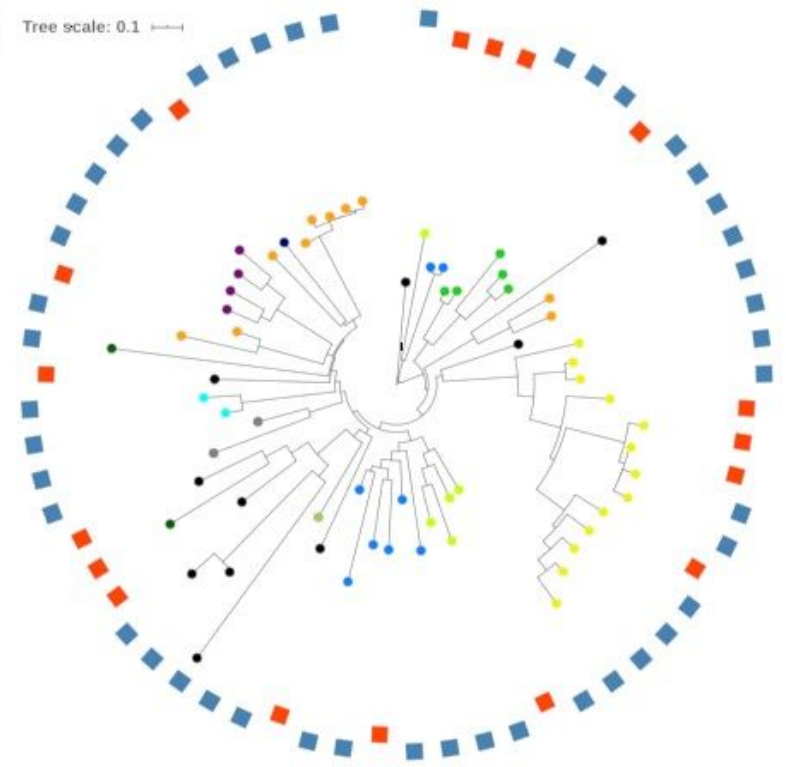

d)

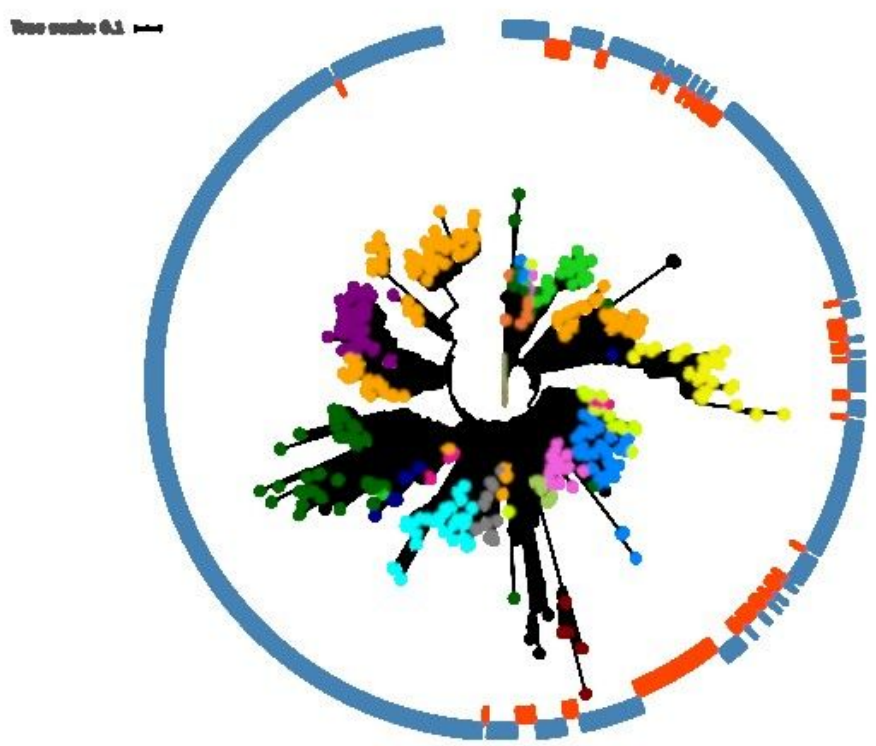

P Levels

Actinobacteria Planctomycetes

Chloroflexi

archaea
Nitrospirae
Armatimonadetes
Gemmatimonadetes
Others
Level 0

- Level 100

Figure 2 
Operational Taxonomic Units (OTUs) enriched in the rhizosphere of common bean. Differential analysis on de novo OTUs obtained from 16S rRNA sequencing comparing optimal supply of $\mathrm{P}$ (L100) and $\mathrm{P}$ depleted condition (LO). Phylogenetic trees showing the differentially enriched OTUs observed in a) IAC Imperador [P-efficient] growing with TSP or b) RPB amendment; c) Dor-364 [P-inefficient] growing with TSP or d) RPB amendment. OTUs are coloured at Phylum level.

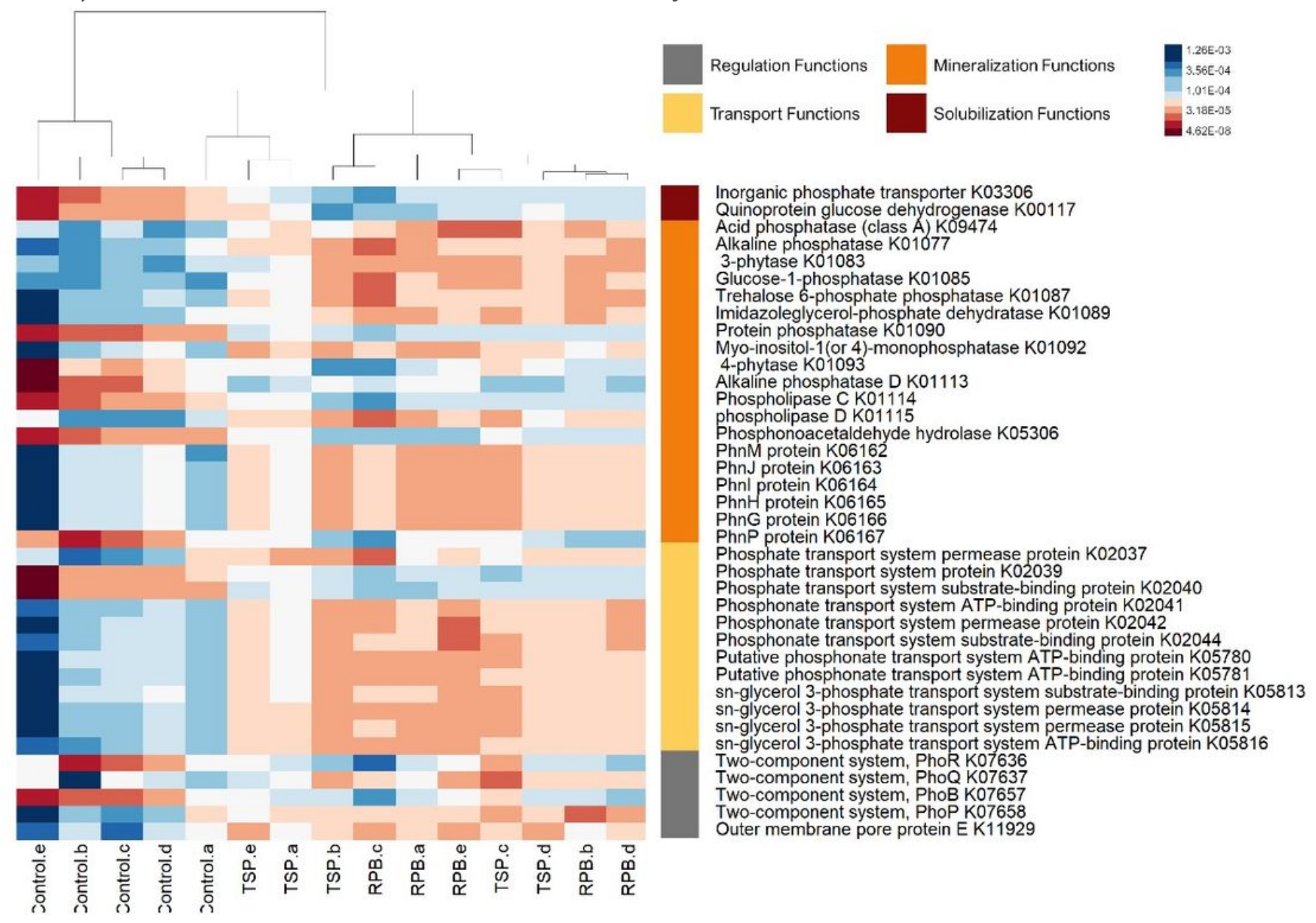

Figure 3

Bacterial functions enriched in the rhizosphere of common bean. Differentially enriched functions of the Dor-364 [P-inefficient] genotype growing under depleted (LO) or optimal (L100) amendment of triple superphosphate (TSP) or phosphate rock Bayovar (RPB). Functions involved in phosphorus cycle were accessed by the predictive metagenomics (Tax4Fun) based on 16S rRNA amplicon sequencing. 
a)

Lo

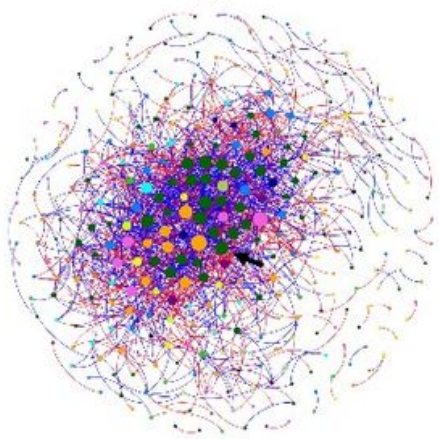

b)

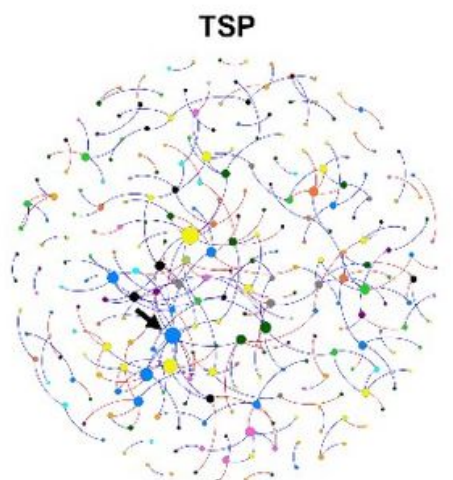

c)

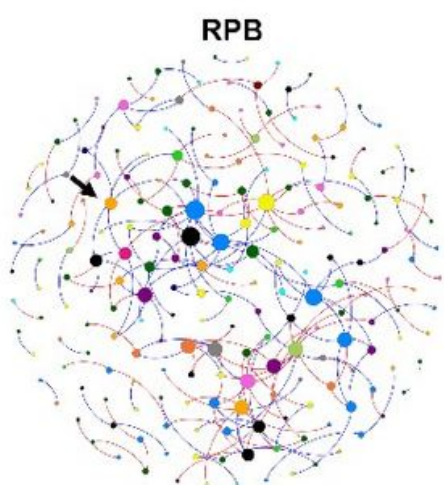

\section{Taxonomy}

\begin{tabular}{llll}
\hline Alphaproteobacteria & Acidobacteria & Actinobacteria & Nitrospirae \\
Betaproteobacteria & Bacteroidetes & Planctomycetes & Armatimonadetes \\
Gamaproteobacteria & Firmicutes & $\square$ Chloroflexi & Gemmatimonadetes \\
Deltaproteobacteria & Verrucomicrobia & archaea & athers
\end{tabular}

\section{Figure 4}

Co-occurrence network analysis of rhizosphere bacterial communities. Analyses were performed for Dor364 [P-Inefficient] cultivated in a) P depleted (L0), or in soil amended with optimal level of b) triple super phosphate (TPS) (L100) or C) rock phosphate Bayovar (RPB) (L100). Blue connections show SPARCC positive correlations $(R 2>0.9 ; p<0.01)$, red connections show SPARCC negative correlations $(R 2<-0.9$, $\mathrm{p}<0.01$ ). The size of the node is proportional to the number of connections it makes (degree). The colours represent different bacterial phyla. Keystone species are identified with black arrows.

\section{Supplementary Files}

This is a list of supplementary files associated with this preprint. Click to download.

- ChiaramontePsupplinfo30jul20.docx 